\title{
The Perception of Class X Students of Phuentsholing Higher Secondary School towards Chemistry
}

Yeshi Nidup

Vice Principal of Phuentsholing Higher Secondary School (PHSS), Bhutan, yeshinidup17@education.gov.bt

Sonam Zangmo

Chemistry teacher of PHSS, Bhutan. Bhutan, sonamzangmoa@education.gov.bt

Yeshey Rinzin

Chemistry teacher of PHSS, Bhutan. Bhutan, yeshirinzin@education.gov.bt

Sangay Yuden

Physics teacher of PHSS, Bhutan. Bhutan, sanyuden@education.gov.bt

Hem Raj Subba

Biology teacher of PHSS, Bhutan. Bhutan, hemrajsubba@education.gov.bt

\section{Jeewan Rai}

Physics teacher of PHSS, Bhutan. Bhutan, eewanrai@education.gov.bt

This research explored the perception towards Chemistry of class ten students of Phuentsholing Higher Secondary School in Bhutan. It was also to find out the factors that influenced the perception of students towards chemistry. For this research, 90 students were chosen as sample from a population of 95 students through convenience sampling technique to maintain $95 \%$ confidence level and 0.025 margin of error. Cronbach's alpha was calculated to be 0.89 during reliability test. A survey questionnaire comprised of 41 items categorized as classroom environment, teaching pedagogy, resources, students' level of interest, and curriculum was used to collect data. A descriptive analysis was done using excel/SPSS. The study concluded that Chemistry is least favourite subject of the students known through survey questionnaire. The classroom environment in the school is found to be conducive and interactive. It was found that Chemistry teacher used different teaching strategy but less of practical work. The study found that students learned more through practical work. It was known that students don't find chemistry practical fun and enjoyable. The findings also indicated that not much of multimedia were used in teaching. Besides, the study revealed that students see Chemistry subjects containing more of abstract ideas and chemical formulas which make learning difficult. Surprisingly, only $30 \%$ (27) students were willing to take up jobs that require knowledge of Chemistry.

Keywords: perception, classroom environment, science curriculum, pedagogy, learning

Citation: Nidup, Y., Zangmo, S., Rinzin, Y., Yuden, S., Subba, H. R., \& Rai, J. (2021). The Perception of Class X Students of Phuentsholing Higher Secondary School towards Chemistry. Anatolian Journal of Education, 6(1), 51-66. https://doi.org/10.29333/aje.2021.614a 


\section{INTRODUCTION}

Bhutan's education system dates back to as early as 1950s in the form of monastic education and modern education began since 1960s with the implementation of first five-year plan in Bhutan (CERD, 2005). Bhutan placed great importance in institutionalizing a relevant and challenging science curriculum for all of its school children. Science was considered important as mentioned in the 'Science Curriculum Framework PP-XII' (DCRD, 2011),

Scientific knowledge accelerates technological development in the country and is therefore, accorded great importance as an area of learning in the formal education system. Knowledge of science is indispensable for every citizen as it is one of the means to help people understand and make sense of the workings of the universe and the natural world around them. The wellbeing and lifestyle of people and of the natural world are greatly affected by the knowledge, skills and values of science that an individual hold (p. iii).

The 'New Approach to Primary Education'(NAPE) was launched in 1986, seeking to orient the primary (class IV to VI) science curriculum to contextualize to Bhutanese context and also to promote the teaching of science based on Bhutan's natural and social environment (DCRD, 2011).

Moreover, the international debates about scientific literacy and the changing time and needs of Bhutanese society and its students have pushed for the review of the science curriculum in Bhutan (Childs, Tenzin, Johnson \& Ramachandran, 2012). Particularly, science education has played a significant role in the socio-economic development and it continues to do so. Over the years, several reforms and changes of curriculum has been done to suit with the rapid development taking place in and around the world.

His Majesty the fifth King of Bhutan, Jigme Khesar Namgyel Wangchuk in his address to the nation specifically mentioned:

It is thus imperative that the country must also bring new plans and preparation to meet the changing realities. He points out that in all the countries where progress has been strong in the areas they strive to develop, the strength of the education system has been in Math and Science. In Bhutan, Mathematics is one of our main weaknesses - most students do not like Math and the majority scores less than $50 \%$. We have similar weaknesses in Science and amazingly, even English (NEF, 2009, p.5).

Thus, science curriculum has also undergone transformation from the beginning of modern education until today.

In the school curricula, science as a subject, therefore, has been accorded high priority, and any decline in the quality of science education in the school system is of great concern for the Ministry of Education. In the drive to keep the school curricula abreast of the changing times and space, the science curriculum reform has been initiated in the $10^{\text {th }}$ five-year plan to update and consolidate the existing science curriculum from classes PP to XII (REC, 2018, p.24).

Students in Bhutan are introduced to science right from primary class, but it is an integrated science until class eight. However, students are oriented to chemistry as the integrated science is infused with all the three disciplines: Physics, Biology, and Chemistry. But students learn chemistry as separate subject only when they reach class 9 since science subject is bifurcated into three disciplines.

Hassan, Ali, Salum, Kassim, Elmoge and Amour (2015) describes chemistry as a subject universally accepted and realized both by students and people who are fond of learning about chemicals. The subject provides broader knowledge about science in general for the individual that aim to study the 
environment or climate change related courses. Moreover, Sirhan (2007) considers chemistry as one of the most important branches of science; it enables learners to understand what happened around them.

But the report of national level examination for both class X and XII for 2016, 2017 and 2018 is not very impressive (BCSEA, Annual Report 2017, 2018, and 2019). On an average taken for three years, mean marks for chemistry for both class X and XII has been the lowest (See Table 1). There could be multiple factors contributing for this low score, but this research will try to study the perception of students towards the subject (chemistry). This may give some ideas to establish a relationship between students' perception towards chemistry and their score in the future.

However, the scope of this study is only to find of the perception of students towards chemistry. This study is not going to find out the relationship between students' perception and their score in the subject.

Table 1

Science mean marks (2017-2019)

\begin{tabular}{lllllll}
\hline \multicolumn{5}{l}{ Class X(BCSE) } & \multicolumn{4}{l}{ Class XII(BHCSE) } \\
\hline Year & Physics & Chemistry & Biology & Physics & Chemistry & Biology \\
\hline 2016 & 50.85 & 45.25 & 51.9 & 55.5 & 49.69 & 56.81 \\
\hline 2017 & 56.05 & 48.43 & 45.73 & 58.51 & 55.97 & 62.95 \\
\hline 2018 & 55.47 & 46.89 & 53.2 & 64.01 & 56.87 & 64.47 \\
\hline Average & 54.12 & 46.86 & 50.28 & 59.34 & 54.18 & 61.4 \\
\hline
\end{tabular}

Source: BCSEA Annual Report, 2017-2019

\section{Literature Review}

Perception, in humans, is defined as the process whereby sensory stimulation is translated into organized experience (West, Dember, \& Epstein (2019). In psychology, perception is referred to the way sensory information is organized, interpreted, and consciously experienced.

Perceptions can be affected by our beliefs, values, prejudices, expectations and life experiences. The shared experiences of people within a given cultural context can have pronounced effects on perception. There are continuous interactions with physical environment and diverse stimuli, which sends different sensations into the body. All these sensations are processed and contribute to a new experience as a result of what is felt, experienced, observed, heard and learned. Consequently, perception is formed.

The students' experience in the classroom, interactions with the students and teachers, students' understanding about the subject and the curriculum matters will strongly determine students' perception about Chemistry. Understanding students perception towards chemistry is important and necessary for both the students and teachers for effective teaching and learning.

Perception, in humans, is defined as the process whereby sensory stimulation is translated into organized experience (West, Dember, \& Epstein (2019). In psychology, perception is referred to the way sensory information is organized, interpreted, and consciously experienced.

Perceptions can be affected by our beliefs, values, prejudices, expectations and life experiences. The shared experiences of people within a given cultural context can have pronounced effects on perception. There are continuous interactions with physical environment and diverse stimuli, which sends different sensations into the body. All these sensations are processed and contribute to a new experience as a result of what is felt, experienced, observed, heard and learned. Consequently, perception is formed. 
The students' experience in the classroom, interactions with the students and teachers, students' understanding about the subject and the curriculum matters will strongly determine students' perception about Chemistry. Although it may vary from person to person, understanding how students perceive the subject is paramount.

In a study by Zigman (2018), four theories of perception are mentioned:

\section{Indirect Realism}

According to indirect realism, in a perceptual experience, there is awareness of mind-dependent objects involved, which in turn is caused by mind-independent objects and events. Mind-independent objects are perceived when people are aware of the mind-dependent objects they cause and represent. People are only indirectly aware of mind-independent objects even if they are perceived. But people are directly aware of mind-dependent objects and the phenomenal qualities that belong to them through experience. Thus, anything that appears to people in experience is due to the internal objects.

\section{Critical Realism}

For the perceptual experience, two components are involved: sensory component, which is a conscious internal state and a conceptual component involving the exercise of classificatory concepts. External objects are perceived by people when they have experienced caused by objects in and around. An experience that includes an inner state that is distinct from the object that caused it. The qualities of these states are what people experience and what appears to them. So, any phenomenal character of experience is determined by this inner state.

\section{Intentionalism}

Intentionalism explains that perceptual experience is a matter of mentally representing the external world. People perceive mind-independent objects when people represent them as being a certain way. So, any qualities people are aware of in perceptual experience are properties of mind-independent objects; they do not belong to some inner state or object, nor are the people aware of something minddependent. This phenomenal character of an experience is said to be due to the representational or intentional properties of the experience.

\section{Naïve Realism}

According to naïve realism, perceptual experience involves the direct awareness of mind-independent objects. Whatever external objects are perceived; they are immediately present to the mind. Mindindependent objects and their properties are constituents of individual's perceptual experiences, and this experience relates the people to the objects. Thus, the phenomenal character of experience is due to mind-independent objects.

\section{Gibson's theory}

According to Gibson's theory, perception is determined by optical flows-optic arrays, considered to be a sort of structures or patterns of light in the environment. In a study by Démuth (2013) mentioned that Gibson believed that a human perceives objects (their sensory qualities) in a way by which packets of information - arrays determined (structured) by objects, enter his sensors. The information about the shape, size, texture, colour, and other associated with the object is carried along with the beam of light that reflects off the surface of an object. Gibson also found that our perception is effected by our active approach besides focusing our attention and perceptual accommodation. Movement is very significant thing for perception.

In a study by Démuth (2013), it is stated that, 
Gibson concluded that by detailed analysis of data collected from the environment we may acquire all the essential information about objects - by direct perception of their perceivable qualities. And this is not only information about their size or structure, but also about their importance and potential application. It is possible to perceive, using senses, the potential use of particular objects the same way as it is possible to perceive the structure of these objects. Affordance is the quality of an object or it is the thing we might be able to do with this object. The core of Gibson's concept is a conviction that our perception is based on information volume of sensory inputs, which we further process only via revealing and explaining the available information (p.27).

Students' perception towards chemistry is an important aspect to know because the perception will influence in the development of attitude towards the subject. As a result, it is going to impact the learning and achievement of the students. In a study by Ali (2012), it is mentioned that most of the children studying chemistry at the secondary level are not satisfied with their experiences of learning in schools because curriculum standards emphasize acquisition of specialized knowledge that needs certain attitudes, frame of mind, and skills on the part of students.

Research in science education has established that students' level of success in learning science is inherently linked with their positive attitude toward science and that has greater impact on the level of motivation they bring to learning the subject (Ali, 2012). According to Woldeamanuel, Atagana \& Engida (2014) students from secondary schools to universities in many countries struggle to learn chemistry and many do not succeed. Even, Madhi (2014) posits that the general perception of chemical education for many people have been described as challenging and difficult to understand. (Ben-Zvi, Eylon \& Silberstein, 1987; Gabel, 1999; Johnstone, 1991; Nakhleh, 1992) as cited in by Cardellini (2012) chemistry is seen as a difficult, complex and an abstract subject that requires special intellectual talents and a too much effort to be understood by many students. This is further supported by Sirhan (2007) as the author mentioned that chemistry topics are generally related to or based on the structure of matter; chemistry proves a difficult subject for many students.

Devetak and Glaz ar (2014) mentions that

There seems to be a mystique about chemistry. Many students do not recognize the chemistry in their everyday lives, many students consider chemistry to be a challenging and difficult subject beyond their capabilities and many students fail to recognize the value of chemistry in their future careers - even for those students who are majoring in a science and especially those who are not majoring in a science (p.25).

According to Johnstone (2000, p. 9) "Chemistry is a difficult subject for students. The difficulties may lie in human learning as well as in the intrinsic nature of the subject." Even Chiu (2005) as cited by Childs and Sheehan (2009) believes that "Chemistry is a world filled with interesting phenomena, appealing experimental activities, and fruitful knowledge for understanding the natural and manufactured world. However, it is complex." Also, Taber (2002) supports that chemistry curricula commonly incorporate many abstract concepts, which are central to further learning in both chemistry and other sciences.

There are several reasons why students find chemistry difficult to learn. Lecture is one of the most common teaching methods in schools. The teachers consider it to be an effective way to present material in a manner in which student learning is mediated by teacher. This method has been described as "a grossly inefficient way of engaging with academic knowledge" (Laurillard, 2002, p. 94). In the traditional lecture, the level of students' involvement in the process of learning can be quite low, and "a major problem with the lecture is that students assume a passive, non-thinking, information receiving role" (McKeachie, 1994, p. 68). The difficulty of learning chemistry can also be 
attributed to use of language which contain lots of jargons and technical terms associated to the subject. Madhi (2014) mentions that the essence of teaching and learning Chemistry is the ability of the teacher to provide experiences that share their expert meanings with novice learners. Both the concepts and knowledge about how to learn Chemistry are included in the expert meanings. According to Khan and Ali (2012), teaching methods, teacher attitude, influence of parents, gender, age, cognitive style of pupils, career interest, and social implication of chemistry and achievement, are some of the factors that influence students' attitude towards chemistry.

The perception of students towards Chemistry is influenced by several conditions but in this study, classroom environment, teaching pedagogy, students' level of interest, Resources and Curriculum were considered to understand their perception.

According to Stewart, Evans and Kaczynski (1997) classroom environment can be categorized into four main factors: (1) physical environment, (2) time/instructional management, (3) behavior management, and (4) teacher effectiveness. Stewart et al., (1997) also argue that "an orderly and attractive environment can have a positive effect on behavior by improving the level and quality of student interactions, so teachers and students carry out activities efficiently without excessive noise or interruption" (p. 53). Landau (2004) too agrees that if the classroom is appealing and has interesting items displayed, it helps the visual learners to do better.

Teachers' behavior in the classroom is also very important. Marzano and Marzano (2003) have found that teachers' actions in their classrooms have twice the impact on student achievement than any other factors contributing to the student's achievement. Wubbles, Breklmans and Hermans (1987) and Shadreck and Isaac (2012) have suggested that cognitive and affective development of students can be strongly influenced by teacher-student interactions. The effectiveness of a teacher can be determined by the ability to establish positive relationships with the students in the class. A teacher can be ineffective if the teacher is not able to communicate with their students. Cano (2001) found that there are significant positive correlations to a learner's ability to learn with the degree of use of classroom time, and the amount of attention given to the students in the class. Also, Hassan, Ali, Salum, Kassim, Elmoge, and Amour (2015) stated the need to strongly emphasize on effective teaching since teacher's role is critical in improving the performance of the student's academic subjects.

In recent years, the content and pedagogy of science education have repeatedly been scrutinized. Teaching pedagogy used by the teacher in the classroom will also influence and affect the perception of students towards the subject. In the $21^{\text {st }}$ century, teacher can no more be a sage on the stage. A teacher must explore and go beyond what is prescribed in the textbook in order to develop higher order skills such as critical thinking, creativity and innovation, problem solving, decision making and collaborative skills which is very important for today's learners. The benefits of using ICT is mentioned by Jegede and Akingbade (2013) that science lesson becomes interesting and easy with the use of ICT in the classroom. Also, that teaching and learning of science become effective with effective application of ICT, thereby improving the performance of science students.

Curriculum is another factor that influences student's perception. In a study by Hassan et al (2015) done at secondary school level found that curriculum is mostly subject centered and does not respond easily to the changing socio-economic environment. Moreover, learning needs and their choices are not met with the frequent addition of secondary. Hofsteinand Naaman (2011) cited the study done by Eilks, Marks, \& Feierabend, 2008; Gräber, 2002; Gilbert, 2006; Millar \& Osborne, 1998 which mentioned that the nature and content of the current curricula-both contents and pedagogies are directly related to the decline in physical sciences in particular (physics and chemistry).

Besides, Gräber (2002) described that science curricula in many countries are being overloaded with content that emphasizes the inner content structure of the related academic discipline. Therefore, not 
much of issues that are relevant to student's everyday life or societal concerns are included in the curriculum (Holbrook, 2005). This results in failure to make connections between the facts and concepts presented and their practical applications. Hence, 'big picture' of science is missed and confidence is never developed in its relevance. All these have potential to influence the attitudes and interests of the learners.

How does student's level of interest influence their perception and their performance? Hofstein and Naaman (2011), vividly explains that students do not make an effort to learn and understand the concepts and theories being taught if students are not interested in science. The student's decisions to study science are determined by their interest in the subject. Moreover, Hofstein and Naaman (2011) assumed that students who are interested in science and understand the scientific concepts, will have more positive attitudes towards science and science studies compared to those who have learning difficulties in the science disciplines. Simpson \& Troost (1982) concluded that people are committed to science when they better understand it and want to take more science courses and to continue reading about science. Even, Fairbrother (2000) claimed that pupils learn only if they want to learn. Hofstein and Naaman (2011) postulate that there is a strong relation between relevance and attitudes toward and interest in the subject they learn. For instance, there is a good chance that students will develop positive attitude towards the subject if the contents that they learn in chemistry are relevant to their daily life and to the society in which they operate.

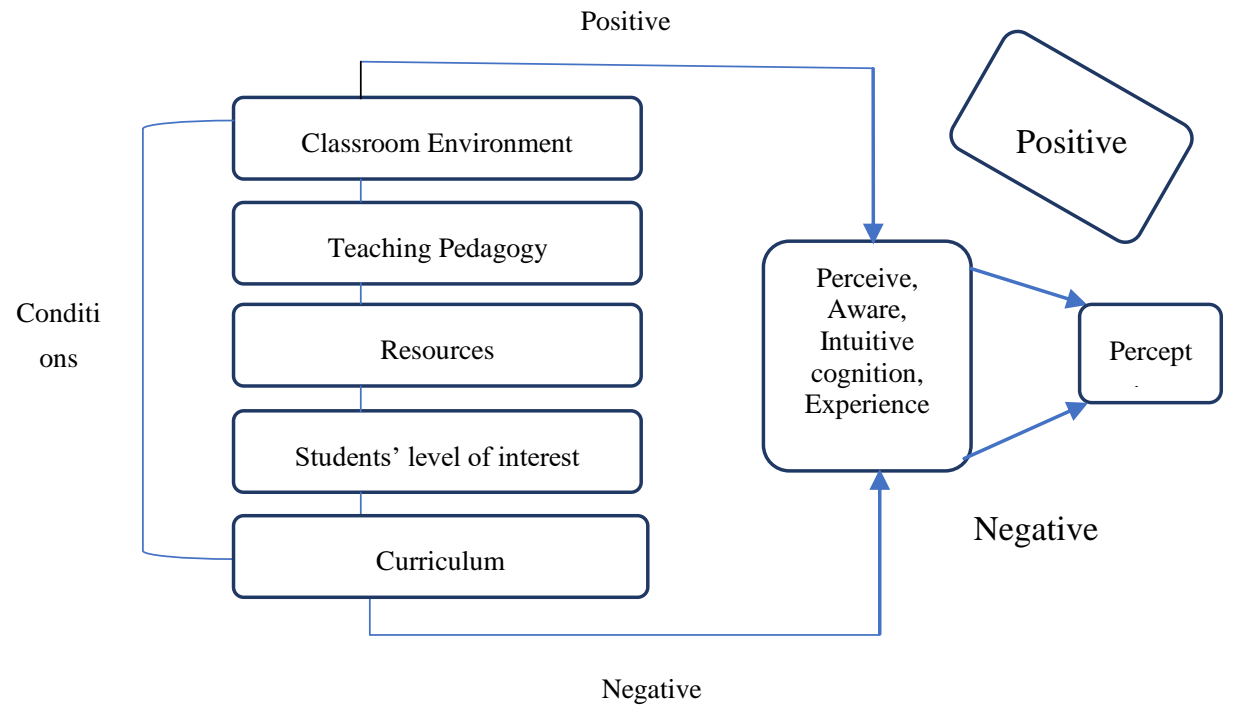

Figure 1

Diagram representing how the perception is developed

\section{METHOD}

The aim of this research was to study the belief and opinion of students about chemistry. The students' perception differs from subject to subject, person to person, and it was important to know their perception of the particular subject. This enabled the teachers to understand how the students perceive about the subject.

The findings from this research was to help science teachers to understand the perception of class ten students towards science, Chemistry in particular. It was also to understand some challenges pertaining 
to classroom environment, teaching pedagogy, resources, curriculum and students' level of interest. This research was also to help the Chemistry teacher, Science department and the school head to plan and implement strategies to overcome some of the challenges mentioned in the study. Through this research, the researchers intended to give some recommendations to the Curriculum developer, Ministry of Education, and Head of Science Department at the higher level to review and make necessary changes in the Curriculum according to the needs of the learners and also relevant to the situation. All in all, this study was expected to benefit other science teachers and students across the country to improve teaching and learning of science and Chemistry. In particular, the findings were expected help the students of this very school to improve their academic learning in Chemistry.

This research was done using quantitative method. The data was collected from large number of students and mathematical computations such as percentages and numbers were used in this study. Amongst many class levels taking chemistry subject, the researchers chose one class $\mathrm{X}$ level for this research purpose. This was done to enable the researchers to conduct the study smoothly as the class was deemed suitable and convenient for the researchers and participants. Aliaga and Gunderson (2002) describes quantitative research as "explaining phenomena by collecting numerical data that are analysed using mathematically based methods (in particular statistics)."

The population for this study comprised of three sections of class ten students of Phuentsholing HSS for the academic year 2019. There were 95 students ( 41 boys and 54 girls). Convenience sampling was used to collect the data for this study. This is a non-probability sampling technique where subjects are selected because of their convenient accessibility and proximity to the researcher. It is also because of the time and resource constraint. However, 90 students were chosen from 95 class X students as sample for this research. This sample size was calculated using Krejice and Morgans table. This sample size fulfilled $95 \%$ confidence level at 0.02 margin of error, according to Krejice and Morgan's table of sample size calculator.

To carry out this study, a survey questionnaire was developed using four-point Likert scale (4-Strongly agree, 3-agree, 2-disagree, 1-strongly disagree) which comprised of 41 items. These items were categorized into classroom environment, teaching pedagogy, resources, students' level of interest and Curriculum. The questionnaire was used to do pilot test and the actual survey.

A survey questionnaire was developed by the researchers after detailed discussion amongst the researchers in consultation to an expert undergoing a $\mathrm{PhD}$ study. The questionnaire comprised of 41 items divided into five groups: Classroom Environment, Teaching Pedagogy, Resources, Students level of interest, and Curriculum. The questionnaire was further validated by a known researcher whose interest is in education, teaching pedagogy and teachers professional development, pursuing $\mathrm{PhD}$ degree at Australia through written feedback and comments. Basically, face validity and content validity was done. Pilot test was also done to establish credible reliability and maintain the standard of the questionnaire. Reliability test was done and Cronbachs alpha was ensured to be more than 0.05 .

For this study, primary data was collected from the sample taken. In order to carry out this study, survey questionnaire was given to all the students and the survey was done at one go in presence of the researchers. General instructions were given before they responded to the survey questions. This was done to ensure quality data input from the respondent's side. On an average, students took 15 minutes to complete the questionnaire.

The data was loaded in Excel and analysis was done. Descriptive analysis was done using Excel/SPSS. Frequencies, percentages and graphs are used to express and also to represent the findings. 


\section{Research Questions}

a) What is the favourite subject of the students?

b) What is the perception of class ten students towards chemistry?

c) What are the factors that influence the perception of the students towards chemistry?

\section{FINDINGS}

\section{Favourite subject}

From the survey response, only $1.1 \%$ (1) participants chose chemistry as their favourite subject. This indicates that students are not interest in chemistry subject. They are interested in other subjects such as Information Technology (IT) which was found to be the favourite subject for $18.8 \%$ (17) participants. In a study by Cuff (2017) show that students chose not to study certain subjects because they perceived them to be difficult. Therefore, their perception, learning curiosity, participation and contribution in learning chemistry will be influenced by the choice of the subjects. Hence, minimum students will show interest, curiosity and take active participation to learn chemistry.

\section{Classroom Environment}

According to Ali (2012),

Complexity of classroom life is important to be considered because students and teachers are expected to collaborate on every aspect of classroom life involving teachers relating to students and students relating to each other through various ways such as discussion, debating, and communicating ideas. The complex interaction between teacher and students and among students constitutes the social context of classroom environment where teachers and students are engaged in a collective process of learning that produces shared understanding and generates new knowledge or perspectives and helps students take responsibility of their own learning (p.3).

$75 \%$ (68) of the participants mentioned that classroom is spacious for learning chemistry, $97 \%$ (88) participants mentioned that they get support from their chemistry teacher. $88.8 \%$ (80) participants mentioned that they can interact freely with their teacher and friends in the class. According to Igwe (2017) learning cannot effectively take place where the environments for learning in terms of social, physical and psychological factors are not conducive. Hence, it is deemed important for a Chemistry teacher to provide conducive environment for learning to effectively take place. The classroom environment seems to be conducive with more space, good support from teacher, and free interactions in the class both with students and teacher. However, 64.4\% (58) mentioned that students in the class are non-cooperative and not positive to learn. This will disrupt the classroom environment and negatively impact on the learning of chemistry. On the contrary, $88 \%$ (80) accepts that they get support from friends in the class. This is possible because they may be supportive at personal level and individual level but not cooperative as a class. Kausar, Kiyani and Suleman (2017) also mentioned the need of supportive learning environment as it contributes to student's achievement and also learners achieve excellently in an encouraged and stimulated classroom environment.

\section{Pedagogies/Teachers teaching practice}

It is understood that chemistry teacher is using different teaching strategies as $96.7 \%$ (87) participants agreed that chemistry teacher uses different teaching strategies. Also, 88.8\% (80) participants agreed that chemistry teacher conducts various learning activities to engage in meaningful learning. The brain breaks are also said to be used by the chemistry teacher in the middle of the lesson to keep the class active. There are more interactions between students and also with the teacher as the participants 
mentioned their chemistry teacher allowed the participants to actively interact during chemistry lessons. It is clear from the respondents that the teacher uses activity-based learning and also $21^{\text {st }}$ century pedagogy. Different learning strategies are used, different learning activities are conducted, brain breaks are used in the middle of the lesson, and students are allowed to interact freely. This caters to different groups of students with diverse learning abilities and helps learners develop critical thinking and encourage cooperative learning.

But $82.2 \%$ (76) participants disagreed that most of the lessons are taught through practical work in the lab. This is important because Woodley (2009) clearly stated that good-quality practical work can engage students, help them to develop important skills, help them to understand the process of scientific investigation, and develop their understanding of concepts.

Besides, 44.4\% (40) participants disagreed that lessons are often taught using video lessons, images and power point presentations. Ludwig, Daniel, Froman and Mathie (2004) mentioned that several dozen studies indicated that computer-based multimedia can improve learning and retention of material presented during a class session or individual study period, as compared to "traditional" lectures or study materials that do not use multimedia.

It is also found that chemistry teacher is not conducting much of lab experiments and not using much of video lessons, images and power point presentation. This can seriously affect the quality teaching and learning of the concepts and theories. Moreover, learners will lose interest and curiosity to learn chemistry if teaching of chemistry is not made exciting and enriching. As Jegede (2007) rightly pointed out that use of unattractive teaching methods leads to student's low motivation to engage in chemistry learning.

\section{Resources}

The resources include the physical classroom and laboratory with good ventilation, availability of good chalkboard, preparatory room, enough chairs and tables, charts and clean environment. The other factors include the presence of instructional materials in the laboratory such as apparatus and chemicals (Owoeye and Yara 2011). The dissemination of information to students through bulletin boards, posters, and charts, if well organized and accessible to students will enhance assimilation and performance in their academics (Owoeye and Yara 2011). To achieve the desired objective of effective teaching of chemistry in secondary schools, operational chemistry laboratory equipments has to be provided.

$100 \%$ (90) of the participants view that it will be easy for them to understand the concepts and theories through lab experiments. This indicates that students like to learn by doing. Interestingly, 50\% (45) of the participants disagreed that learning of chemistry will be better if there are good internet facilities in the school. Moreover, 38.8\% (35) disagreed that there should be more access to internet and computers in the school. This shows that students don't like to learn theoretically. Also, 78.8\% (71) participants disagreed that learning of chemistry will be fun and realistic through the use of chemicals and apparatus in the lab. This may be because of the complex and sophisticated apparatus that they have to handle which makes learning chemistry difficult, uninteresting and boring for them. Moreover, most of the time, chemicals do not give accurate and expected result. This frustrates the learner rather than make them curious. 70\% (63) participants accept that adequate materials like chart paper, chart models, models, specimens, chemicals, apparatus will enhance learning of chemistry. Resource is a powerful teaching material; although it is not real, but learners can feel, see, touch and view it just like a real thing. So, this helps them to conceptualize and visualize. 


\section{Students level of interest}

$85.5 \%$ (77) of the participants mentioned that they know all the job opportunities available in the future if they take up chemistry and $51.1 \%$ (46) agreed that chemistry will be useful in their life. Despite this, the level of interest is moderate because there are still $31.1 \%$ (28) participants who disagree that chemistry will be useful in their life. Moreover only $28.8 \%$ (26) participants indicated that they would like to take up a job that requires good knowledge of chemistry. This is just a quarter of participants who is interested to take up jobs that are related to chemistry.

For $44.4 \%$ (40) participants, missing chemistry class does not make them feel sad. However, there are $77.7 \%$ (70) of them who mentioned that they are curious to learn more about chemistry and 90\% (81) of the participants responded that they enjoy chemistry classes. Curiosity and enjoyment can combinedly boost the interest of an individual to learn chemistry. Moreover, $70 \%$ (63) mentioned that they take part in every activity during the chemistry class. This would be significant in the learning of chemistry because curiosity drives the learners to explore and learn science and more so through the active participation and experimentation. 86.6\% (78) of the participants agreed that they always try to get help from their friends to learn. This indicates the interest of the participants to learn. In this matter, their learning will be influenced by their friend's willingness to help, knowledge, attitude, relationship and the level of interactions.

\section{Curriculum}

$85.5 \%$ (77) participants agreed that the topics included are interesting to learn. The chapters are also found to be linked with their previous knowledge as mentioned by $94.4 \%$ (85) of the participants. $70 \%$ (63) of the participants agreed that there are lots of formulas, symbols and calculations to be learnt. There are $26.6 \%$ (24) participants who think that the topics are not related to their everyday activities. On the flipside, $56.6 \%$ (51) of the participants thinks that the topics are all related to their everyday activities. This variance in views may be attributed to personal interest and understanding of the subject. $77.7 \%$ (70) participants feel that the topics to be learnt are vast. This could affect the students' attitude toward chemistry, indicating a low level of student motivation to engage in chemistry learning, due to difficulty of the chemistry course and wide coverage of the syllabus in combination with little allocated teaching time (Jegede, 2007).

In addition, $67.7 \%$ (61) considered that chemistry is more of abstract ideas and concepts which are difficult to understand. Taber (2003) posits that Chemistry is a very conceptual subject, and many of its concepts are rather abstract. According to Mahdi (2014),

Difficulty in learning Chemistry may be related to the fact that Chemistry involves different terminologies, structures and calculations. The learning of these elements, for many teachers and students may cause different levels of difficulties.

Moreover, many students view chemistry as a difficult, complex and an abstract subject that requires special intellectual talents and a too much effort to be understood (Cardellini, 2012). 61.1\% (55) participants mentioned that chemistry is not easy to learn. Chemistry is known to be a difficult subject to many students because most of the topics are generally related to or based on the structure of matter (Sirhan, 2007).The vastness of the topics to be learnt and the subject having more of abstract ideas and concepts could be some of the reasons why participants find chemistry difficult to learn. 


\section{CONCLUSION AND DISCUSSION}

\section{Favourite subject}

The research found that Chemistry subject is the least popular amongst all the other subjects. Chemistry turned out to be favourite subject of only 1 out of 90 students. Generally, students perceive that Chemistry is a difficult subject and require a lot of effort in learning. Hence, it appears that they opt for easier subjects such as Information and Technology (IT) as their favourite subject.

\section{Classroom Environment}

The research found the classroom environment conducive and interactive. There is also good relationship between the teacher and the students; there are free interactions in the class. This enables and encourages the students to be more open and positive in learning. There is good support system among the teacher and the students. The students are seeking help from their teacher and friends as and when they face difficulty in learning of chemistry. This culture is important because they can learn from each other through interactions.

On the contrary, the research found that there is lack of cooperation amongst the students and some of them are not positive towards learning. If the learners cooperate and be positive, they will be able to handle complex problems and accomplish any task with less difficulty. It is always better to work as a team to achieve their learning goals than to work individually.

\section{Pedagogy}

Teaching pedagogy used by the teacher matters a lot in teaching and learning process. This research found that different teaching strategy is being used by the chemistry teacher with varied learning activity. It is widely known and accepted that students learn better by doing than listening to lectures. It is also important to have short breaks for the students in the middle of teaching-learning process. For this, different brain break activities are used by the teacher. This allows the students to refresh their minds and prepare for the next activity. Besides, it allows the students for interactions and bonding which will be useful in team building.

On the other hand, many students opined that not much of the lesson is taught through practical work. For science subject particularly chemistry, practical work would make significant difference in understanding of concepts and chemical processes. This will also help the teachers to engage students in scientific work and develop skills to carry out science experiments. There is also less use of video lessons, images and power point presentation. Several studies showed that use of multimedia in teaching can improve learning and retention of material presented during the session. It is also inclusive because different students have different styles of learning. Some learn through visuals, audio, reading, writing, listening, practical, lectures, and more. Therefore, use of attractive teaching pedagogy will motivate and engage the students in learning of Chemistry.

\section{Resources}

The availability of resources in the school plays a vital role on teaching and learning processes. Resources include the availability of good chalkboard, preparatory room, enough chairs and tables, charts and clean environment. Other important resources include the presence of instructional materials in the laboratory such as apparatus and chemicals. The presence of bulletin boards, posters, and charts will enhance assimilation and performance in their academics. Besides, operational chemistry laboratory equipment has to be provided for effective teaching of chemistry in the schools.

In this research, the students viewed that it will be easy for them to understand the concepts and theories through lab experiments. More practical work is preferred in order to engage the students 
meaningfully in understanding of the concepts and theories. But the study also showed that students view that learning of chemistry is not fun through the use of chemicals and apparatus in the lab. This could be because students do not get an opportunity to handle the apparatus often. So, they are not familiar with the equipment's and apparatus in the lab. It is also because there is some apparatus which is used to carry out complex experiments which is difficult to handle. Moreover, the chemicals that are used in the lab do not give the exact result as expected. All these affect the development of student's attitude towards science practical. In this study, large section of the students accepted that adequate materials like chart paper, chart models, models, specimens, chemicals, apparatus will enhance learning of chemistry. These are powerful teaching materials; although they are not real, but learners can feel, see, touch and view it just like a real thing. So, this helps them to conceptualize and visualize. Interestingly, only half the population indicated that learning of Chemistry will be better if the Internet facilities in the school are good. The chemistry teacher should now enhance the use of ICT and Internet facilities to let the students feel and understand the role of internet in teaching and learning of Chemistry.

\section{Students interest}

The awareness about the job opportunities available in the future if they take up chemistry is good. The study found that only around $30 \%$ (28) of the students are willing to take up job that requires sound knowledge of chemistry. Around $3031.1 \%$ (28) students think that Chemistry is not useful in their life. Almost $78 \%$ of the students are curious to learn more about chemistry and $90 \%$ of the students are enjoying during the chemistry class. This would be significant in the learning of chemistry because curiosity drives the learners to explore and learn science and more so through the active participation and experimentation. The learning is not limited only to the teaching by the subject teacher; it can also be learned through friends and self-exploration. Therefore, 86.6\% (78) of the students indicated that they always try to get help from their friends to learn is a positive signal for self-learning.

In this research, more than $85 \%$ (77) participants viewed that the topics included are interesting to learn and more than $94 \%$ (85) students mentioned that the chapters are also linked with their previous knowledge. The linking of the chapters with their previous knowledge is crucial to establish a good foundation and building on the existing knowledge. As revealed by this study, majority of the students mentioned that there is lots of formulas, symbols and calculations to be learnt. There are $77.7 \%$ (70) participants who feels that the topics to be learnt are vast. This could demotivate the students to engage in learning of chemistry.

\section{Curriculum}

In addition, $67.7 \%$ (61) felt that chemistry is more of abstract ideas and concepts which are difficult to understand. Another $61.1 \%$ (55) participants mentioned that chemistry is not easy to learn. Chemistry is known to be a difficult subject to many students because most of the topics are generally related to or based on the structure of matter (Sirhan, 2007). The vastness of the topics to be learnt, more formulas and calculations, and the subject having more of abstract ideas and concepts could be some of the reasons why participants find chemistry difficult to learn and less interesting. This is also linked with the choice of chemistry as their favourite subject which was the least amongst other subjects. 


\section{RECOMMENDATION}

There is a need for the chemistry teacher, curriculum developer and Ministry of Education (MoE) to make Chemistry interesting for the learners.

The subject teacher and the school have to give more attention to team building activities so that the students can be more cooperative and collaborative in doing group activities.

The frequency of practical work has to be increased and more relevant experiments needed to be designed in order to suit with the demands of the students learning.

The use of multimedia such as video lesson, power point presentations, images, audio records, and other relevant medium need to be enhanced and encouraged in the school. The integration of ICT in teaching and learning will have more impact on the learning of chemistry in particular.

The school and MoE need to provide adequate and relevant resources needed for teaching and learning of Chemistry. The key to successful teaching and learning of chemistry depends on the availability of resources, too.

The teacher and relevant organization need to make the students aware of the future prospects of learning chemistry and also make the students understand the importance of the subject knowledge in detail.

The curriculum developer, designers, MoE, and other stakeholders need to review the curriculum and explore the possibilities to reduce the vastness and make the concepts more concrete so that it becomes easier for the learners.

\section{REFERENCES}

Ali, T. (2012). A Case Study of the Common Difficulties Experienced by High School Students in Chemistry Classroom in Gilgit-Baltistan (Pakistan). SAGE Open, 2(2), 215824401244729.doi:10.1177/2158244012447299

Aliaga, M. \& Gunderson, B. (2002). Interactive statistics. New Jersey: Prentice Hall. Provides introduction of basic statistical methods with its strong emphasis on data analysis, also describes how to understand and interpret a variety of statistical results.

BCSEA. (2017). Pupil Performance Report 2016 (Volume 10). School Examination Division, BCSEA, Ministry of Education, Bhutan.

BCSEA. (2018). Pupil Performance Report 2017 (Volume 11). School Examination Division, BCSEA, Ministry of Education, Bhutan.

BCSEA. (2019). Pupil Performance Report 2018 (Volume 12). School Examination Division, BCSEA, Ministry of Education, Bhutan.

Cardellini, L., (2012). Chemistry: Why the Subject is Difficult? Educación Química, 23, 305-310. doi:10.1016/s0187-893x(17)30158-1

CERD. (2005). School library development in Bhutan. Lighting the Lamp School Library Development in Bhutan. Retrieved from https://www.pce.edu.bt/wpcontent/uploads/2017/09/Yonteon-Volume-II.pdf 
Childs, A., Tenzin, W., Johnson, D., \& Ramachandran, K. (2012). Science Education in Bhutan: Issues and challenges. International Journal of Science Education, 34(3), 375-400. doi:10.1080/09500693.2011.626461

Cuff, B. M. (2017). Perceptions of subject difficulty and subject choices: Are the two linked, and if so, how? (Ofqual/17/6288) Ofqual.

DCRD. (2011). Science Curriculum Framework Classes PP- XII. Thimphu: Ministry of Education, Royal Government of Bhutan.

Hassan, A. A., Ali, H. I., Salum, A. A., Kassim, A. M., Elmoge, Y. N., \& Amour, A. A. (2015). Factors Affecting Students' Performance in Chemistry: Case Study in Zanzibar Secondary Schools. International Journal of Educational and Pedagogical Sciences, 9(11), 4086-4093.

Igwe, I. O. (2017). Students' Perception of Chemistry Teachers' Characteristics of Interest, Attitude and Subject Mastery in the Teaching of Chemistry in Senior Secondary Schools. Journal of Chemistry: Education Research and Practice, 1(1), 1-8. doi:10.33140/jcerp/01/01/00002

Jegede, S. A., (2007). Students' anxiety towards the learning of Chemistry in some Nigerian secondary schools, Educational Study and Review, 2(7), 193-197.

Kausar, A., Kiyani, A. I., \& Suleman, Q. (2017). Effect of Classroom Environment on the Academic Achievement of Secondary School Students in the Subject of Pakistan Studies at Secondary Level in Rawalpindi District, Pakistan. Journal of Education and Practice, 8(24), 56-63.

Ludwig, T. E., Daniel, D. B., Froman, R., \& Mathie, V. A. (2004). Using Multimedia In Classroom Presentations: Best Principles. Society for the Teaching of Psychology: Pedagogical Innovations Task Force.

Mahdi, G. J., (2014). Student Attitudes towards Chemistry: An Examination of Choices and Preferences. American Journal of Educational Research, 2(6), 351-356. doi:10.12691/education-26-3.

NAB. (2014). The Bhutanese Democracy: The Vision of a King. The Legislative Journal, 2(2), 12-15.

NEF. (2009). National Education Framework Curricular Perspective. Retrieved from MoE, Thimphu: Bhutan website: http://www.ibe.unesco.org/sites/default/files/Renewing_School_Education_in_Bhutan.pdf

NSB. (2018). 2017 POPULATION \& HOUSING CENSUS OF BHUTAN. Retrieved from National Statistics Bureau, Thimphu, Royal Government of Bhutan website: http://www.nsb.gov.bt/main/main.php

Owoeye, J. S., \& Yara, P. O. (2011). School Facilities and Academic Achievement of Secondary School Agricultural Science in Ekiti State, Nigeria. Asian Social Science, 7(7). doi:10.5539/ass.v7n7p64

REC. (2018). Science Curriculum Framework for PP-XII. Paro, Bhutan: Royal Education Council (REC).

Sirhan, G. (2007). Learning Difficulties in Chemistry: An Overview. TURKISH SCIENCE EDUCATION, 4(2), 2-20. Retrieved from http://www.tused.org 
Taber, K. S., (2003). Understanding ionisation energy: physical, chemical and alternative conceptions. Chemistry Education: Research and Practice, 4(2), 149-169.

West, L. J., Dember, W. N., \& Epstein, W. (2019). Perception. In ENCYCLOPEDIA BRITANNICA. (C)2019 Encyclopedia Britannica, Inc.

Woodley, E. (2009, December). Practical work in school science - why is it important? Retrieved:http://www.gettingpractical.org.uk/documents/EmmaWoodleyarticle.pdf 